\title{
Conceptual framework and background
}

2.1 The power sector supply chain and regulatory environment of smart grids - 8

2.2 The role of regulation and technological progress for the development of electric power systems - 10

2.3 Smart grids - promising technological innovations - 13

References - 16 
Chapter at a glance

- The study's conceptual framework is presented.

- This chapter illustrates the role of regulation and technological progress for the development of the electric power system and introduces the energy policy triangle covering the three main energy policy goals reliability, affordability, and sustainability.

- The concept of and the motivation for smart grids are introduced.

- Fundamental premises highlighting the role of the government and new market actors in the smart grid development process are presented.

\subsection{The power sector supply chain and regulatory environment of smart grids}

The supply chain model of the electric power sector The delivery of electricity from generation sources to end consumers involves a multitude of technologies, actors, and processes, especially in the context of the development of an intelligent futureoriented power grid infrastructure. Therefore, it is useful to employ a supply chain model of the electric power sector (or electricity system) to structure the debate on smart grids.

In this study, a smart grid supply chain model (see - Fig. 2.1) is used to structure the discussion on China's and Germany's power systems along with their most pressing problems and challenges as well as their particular approach of how to promote the development of smart grids. The model subdivides all activities/processes, technologies, and actors of the power sector supply (or value) chain into four basic elements: ${ }^{1}$

- Power Generation: the technical generation of electricity using various kinds of primary energy sources (such as coal, gas, nuclear, hydro,

1 The smart grid supply chain model being referred to in this study is based on the so-called Energy Process Management (EPM) model [16]. wind, and solar energy) and corresponding ancillary services. ${ }^{2}$

- Power Logistics: the transmission, distribution, storage, and metering of electricity.

- Power Trade \& Retail: purchasing, trading, and selling electricity, as well as retail and billing services for end consumers.

- Power Consumption: the end use of electricity by different end-user segments, e.g. rural and urban households, industrial and commercial consumers.

To capture the importance of ICT for transforming the traditional power sector into a smart grid, a corresponding fifth element is added to the model:

- Information \& Communication: operating, monitoring, and controlling power system components, as well as power system-related information exchange between various market actors with the help of ICT along all four stages of the power sector supply chain.

The government plays a pivotal role in the smart grid development process (see Sect. 2.3) as a guiding and supervising key player affecting processes and businesses across all five supply chain elements.

The regulatory environment of smart grids In the remainder of this study, six regulatory areas will be used to describe the regulatory environments of China's and Germany's power systems.

The six regulatory areas are:

\section{- Policy Setting and Fundamental Institutions:}

Government leadership in form of policies, laws, and regulation is essential to promote smart grid development. To practice such a leadership, a governance structure with clearly assigned roles and responsibilities for the field of (smart) grid regulation is of crucial importance.

- Market Structure: The (market) structure of the electric power sector is characterized by all

2 Ancillary services are functions performed by the equipment and people generating, controlling, transmitting, and distributing electricity with the intention of supporting basic services of generating capacity, energy supply, and power delivery [17]. Examples are load following, scheduling and dispatch, real-power loss replacement, and voltage control (e.g. by means of reactive power supply). 


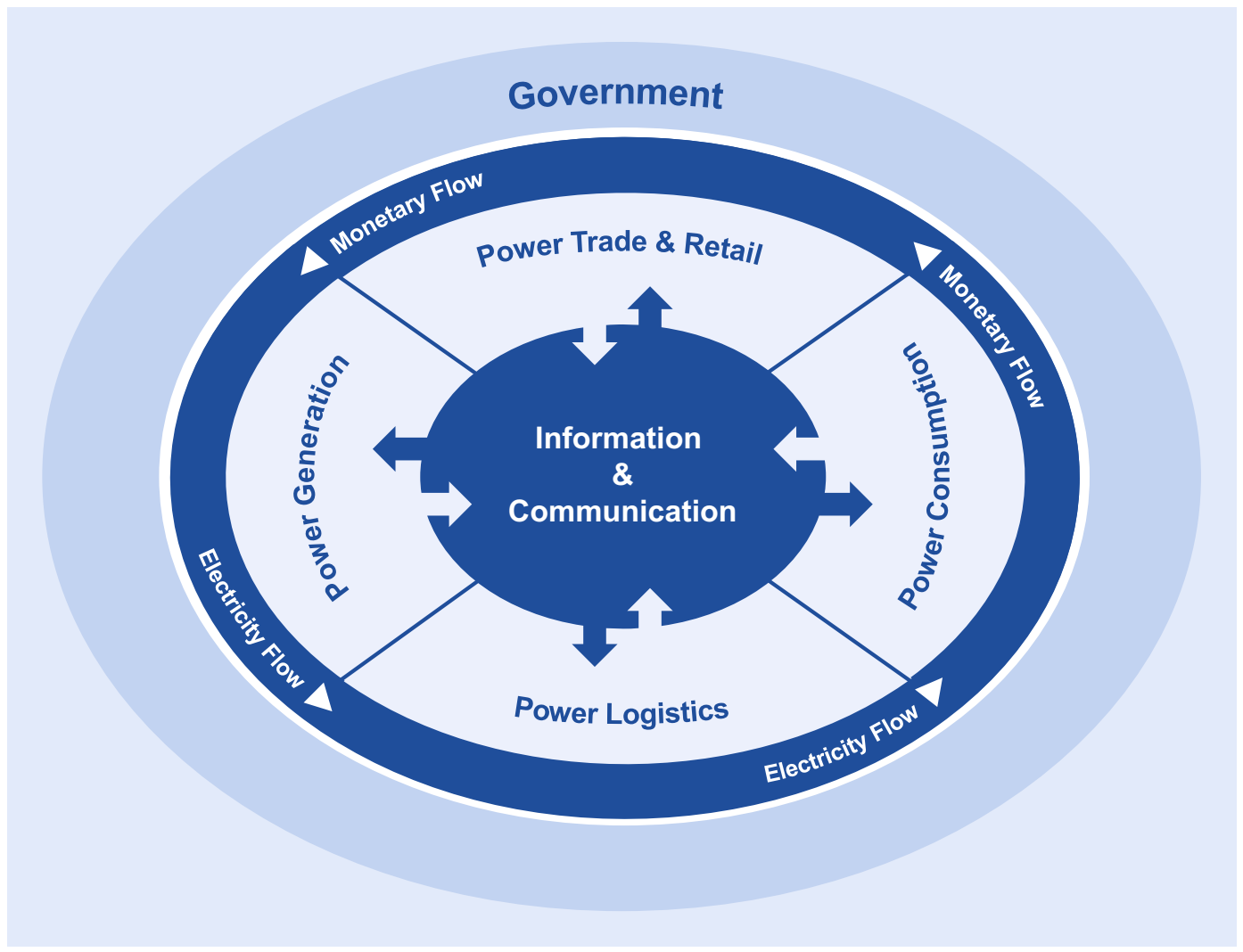

- Fig. 2.1 Electric power sector supply chain model

the companies involved in the various stages of the power sector supply chain from Power Generation and Power Logistics to Power Trade \& Retail (vertical market structure), the market composition and competitive conditions at different stages of the supply chain (horizontal market structure), and the roles and responsibilities of the market actors.

- Market Design and RES Integration: Electricity prices (for generation and retail) are of crucial importance with regard to the utilization of different sources of power generation, investment decisions for new generation capacities, power consumption patterns, and investments in power saving technologies. By setting monetary incentives for investments into power generation capacities, generation electricity prices contribute particularly to the long-term coordination of power generation and consumption. At the same time, retail electricity prices have the power to directly affect the patterns of electricity consumption of end users. The formation of electricity prices is heavily affected by the market structure and the underlying market design, the latter of which is generally defined by the government. Feed-in tariffs for RES and associated regulations are also part of the market design because they represent nothing less than prices for electricity generation fixed by the government.

- Development of Infrastructure and Network Regulation: The regulatory domain explains how investments in the (smart) grid infrastructure can be incentivized through power grid or network regulation. These regulatory practices directly impact the stable and affordable operation of the current grid infrastructure and the investments in the future grid infrastructure.

- Coordination of Generation and Consumption: In this regulatory area, government policies for 
balancing electricity generation and consumption in the short term are described. Many smart grid-related technologies facilitate the balancing of generation and consumption.

- The Role of Information and Communication: Integration of ICT with power system components across the supply chain is a key factor in smart grid development. This regulatory area covers the relevance of ICT companies, standardization issues, cyber security, and funding of smart grid research.

\subsection{The role of regulation and technological progress for the development of electric power systems}

Regulation in the electric power sector Competition, where feasible free from government intervention, is generally considered as a very effective way of reducing production costs, improving quality of supply, and increasing product diversity [1], [2]. Yet, competition is not always feasible. Especially where natural monopolies prevail, competition cannot exist and government regulation is necessary [3].

Transmission and distribution grids are such natural monopolies. Having an infrastructure of overlapping power grids from different competitive suppliers would be economically inefficient. Due to economies of scale, a single supplier (the monopolist) is able to offer the services of the electric power grid at lower costs. However, the monopolistic grid operator has a strong incentive to set high prices for its services or to scrimp on quality. Thus, the price and quality of service of the monopolistic grid operator must be regulated to protect grid users against the monopolist's market power [3]. ${ }^{3}$

3 Note that, at the beginning of the electrification process, the power generation sector was also recognized as a natural monopoly: in the absence of power transmission lines, competition between power generation units from different cities or regions was not possible. With the rather small electricity demand in separated cities or regions, one larger power plant was able to provide the electric power at lower costs than many small competitive power plants due to economies of scale. However, the gradual deployment of transmission lines allowed competition between large power plants to evolve in such a manner that power generation is no longer considered to be a natural monopoly [3].
It is common to distinguish two related goals of monopoly regulation [3] which are both typically tasks for the regulator, like the Federal Network Agency for Electricity, Gas, Telecommunications, Post and Railway (BNetzA) in Germany:

- Control of revenues and prices of the networks (i.e. network charges)

- Secure access to the monopolistic infrastructure (i.e. the network) to facilitate competition among market actors in the commercial parts of the electricity value chain (e.g. generation, trade and retail).

Moreover, the internalization of so-called externalities is a frequently cited argument in favor of government intervention even in the non-monopolistic parts of the electric power system:

- Negative externalities: the generation of electricity is often connected to emissions of environmental pollutants. Without government intervention, neither producers nor consumers of electricity are sufficiently incentivized to behave in an environmentally friendly manner. Therefore, actions of the government such as pollution control laws, energy taxes, and subsidies for environmentally friendly technologies are used to reign in commercial activities and advance the overall societal objectives like environment protection and sustainable development [1].

- Positive externalities: technological progress critically depends on the creation of new knowledge. After its creation, knowledge can be used over and over by various actors with almost no extra costs. From the perspective of the whole society, companies often do not invest enough in knowledge creation because a significant portion of the benefits related to knowledge creation accrues to outside stakeholders, e.g. other companies, institutions, or citizens. In this light, government actions such as a patent law, a stringent protection of intellectual property rights, or the subsidization of $\mathrm{R} \& \mathrm{D}$ can be employed to incentivize companies to invest in knowledge creation and innovation.

This study adopts a broad understanding of regulation and does not only focus on network regulation 
but also upon aspects such as RES integration, innovation policies, and standardization.

\section{A stylized history of power system develop-} ment The historical development of electric power systems dates back to the last decades of the $19^{\text {th }}$ century in the world's most advanced countries of that era. The electrification process in these countries was mostly accomplished by the mid- $20^{\text {th }}$ century, when almost the whole population had access to electric power. In less developed regions, the electrification process started somewhat later and progressed at a considerably slower pace. Differences in onset and pace of the electrification process between countries can be explained mainly with technological, economic, political, and regulatory reasons [4].

In developing their electric power systems, many countries followed a similar stylized pathway. At the beginning of the electrification process, the emergence of new technologies and appliances consuming electric power led to a rapidly increasing demand for electricity. Thus, the main objective was to connect a growing number of consumers as quickly as possible to the electric power grid. The build-up process took place in a rather uncoordinated manner with only little government intervention. Thus, various small-sized companies set up overlapping infrastructures such as small-sized power plants and distribution lines. This uncoordinated set-up phase was often associated with low power quality and reliability as well as high costs. Therefore, governments started to regulate the electricity sector with the intention of making power supply more reliable and affordable. Formally assigning monopoly rights to power generation companies and grid operators created economies of scale, which reduced the overall production costs of electric power generation and distribution. After this assignment of monopoly rights, electricity market regulation became a decisive factor to protect consumers against the market power of the newly installed monopolies.

When a certain level of wealth and economic development had been achieved, the awareness of environmental protection increased in many societies. ${ }^{4}$ Therefore, more emphasis was put on ecological

4 The positive correlation between economic development and environmental preferences has been well documented during the last two decades [18]. sustainability of the electric power system and many governments introduced environmental protection policies.

The energy policy triangle The schematic history presented above reveals that different objectives and regulations were prioritized at different development stages of the power system. Whereas the provision of widespread and reliable access to electricity was often the initial motivation, affordability of electric power emerged as a second driver of energy policy after the initial build-up phase. Finally, the ecological sustainability of the electric power system has often been formulated as a third important priority.

Today, governments strive to incorporate all three objectives in their power sector regulation. They (1) want to provide a reliable and secure electricity supply for their economies, (2) simultaneously promote economic development by ensuring affordable electricity prices while (3) also achieving ecological sustainability. The three goals reliability, affordability, and sustainability are commonly referred to as the energy policy triangle (see - Fig. 2.2).

Conflicting nature of the energy policy triangle There are inherent conflicts between the goals of the energy policy triangle. A government forcing owners of fossil-fuel power plants to install filter technologies for the sake of improving air quality, for instance, is accepting that costs of power generation increase. Another government using expensive domestic resources for electricity generation instead of lower-priced resources available on world markets accepts higher generation costs for the sake of independent and predictable energy supply.

The complete and simultaneous achievement of all three policy goals is virtually impossible. Therefore, most countries place a priority on one or sometimes two policy goals, trying to achieve or maintain acceptable levels with regard to the nonprioritized policy goals. In recent years, the Chinese government, for example, prioritized (1) providing a reliable and secure electricity supply and (2) keeping electricity prices for the population at an affordable level. On the other hand, it has accepted high levels of environmental pollution. The German government, in contrast, has been placing a strong 


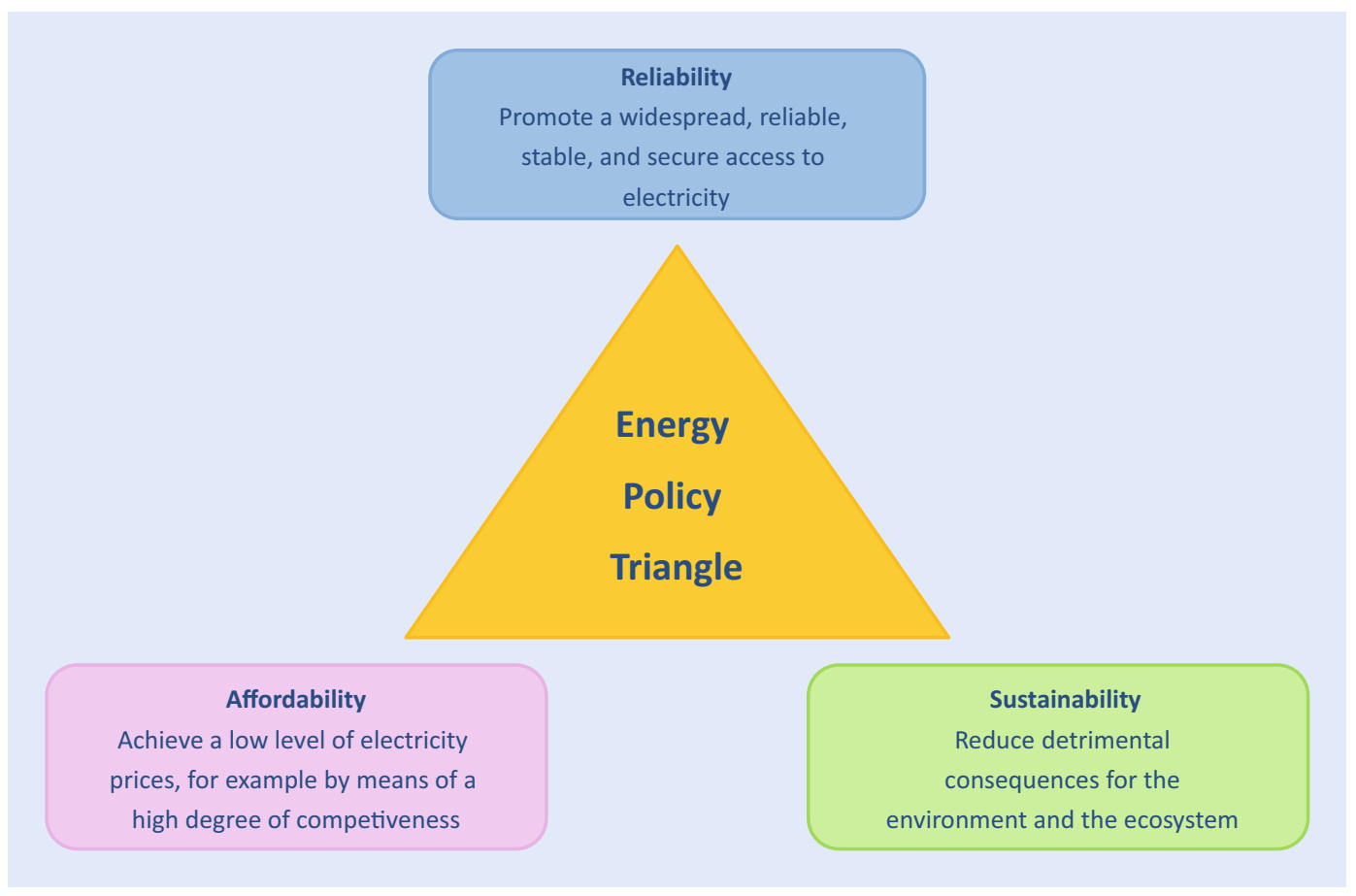

Fig. 2.2 Energy policy triangle

emphasis on ecological sustainability since the end of the $20^{\text {th }}$ century. A prominent strategic decision in this context was the build-up of RES generation capacities so that currently approximately one fourth of Germany's electricity comes from RES [5]. The high share of RES in Germany currently leads to increasing challenges with regard to the policy goals of reliability and affordability. However, both conflicts may be mitigated by means of technological progress as well as smart design of policies and regulatory framework:

- In most cases, electricity generated by means of RES, so-called RES-E, is still more expensive than electricity generated in fossil fuel-fired power plants. This difference in generation costs has contributed significantly to climbing end consumer prices for electricity in recent years. Nonetheless, RES-E is often already cheaper than electricity retail prices (known as grid parity) depending on the characteristics of location and end-user segment. The costs of RES-E have decreased considerably during the last few decades and are projected to decrease even more with further technological advancement and economies of scale through worldwide deployment [6]. Someday, the costs of renewably generated electricity will consequently fall below those of electricity generated in conventional power plants. From that time on, investments in RES will increase both sustainability and affordability of the power system provided that the power system and market design allow for a minimizing of grid integration costs.

- With a rising of electric power generated by variable RES, more and more efforts have to be undertaken to guarantee the high stability and reliability of the power system. Below, two examples of temporary RES penetration in Germany, a power system with electricity loads commonly ranging from 40 to $80 \mathrm{GW}$, are presented: on December $5^{\text {th }} 2013$, a particularly windy day, roughly $27 \mathrm{GW}$ of feed-in was generated by means of wind turbines in Germany [7]. On March $9^{\text {th }} 2014$, a very sunny day, photovoltaic (PV) installations alone fed a 
peak power of almost $22 \mathrm{GW}$ into the grid [7]. Technological progress as well as adaptations to the existing design of the electricity market in Germany are essential to limit the cost of the ongoing transition towards a low carbon economy.

\subsection{Smart grids - promising technological innovations}

The concept of smart grids The capabilities of conventional power grids to cope with many of today's technological challenges, e.g. the integration of a large share of electricity generated by means of intermittent RES, are limited or can only be maintained with significant investments. In this light, smart grids represent a promising new technological concept. Today, the general understanding regarding the concept of smart grids seems to converge on a global level. A definition of smart grids which has found widespread acclaim in the professional community comes from the International Energy Agency (IEA) [8]:

I) An electricity network that uses digital and other advanced technologies to monitor and manage the transport of electricity from all generation sources to meet the varying electricity demands of end users. Smart grids co-ordinate the needs and capabilities of all generators, grid operators, end users and electricity market stakeholders to operate all parts of the system as efficiently as possible, minimizing costs and environmental impacts while maximizing system reliability, resilience and stability.

Another explanation of the smart grid concept comes from the International Electrotechnical Commission (IEC) [9]:

I) The general understanding is that the Smart Grid is the concept of modernizing the electric grid. The Smart Grid comprises everything related to the electric system in between any point of generation and any point of consumption. Through the addition of Smart Grid technologies the grid becomes more flexible, interactive and is able to provide real time feedback.

\begin{abstract}
It is an electricity network that can intelligently integrate the actions of all users connected to it generators, consumers and those that do both - in order to efficiently deliver sustainable, economic and secure electricity supplies.
\end{abstract}

Irrespective of the common general understanding of smart grids, the specific vision of smart grids differs substantially from case to case and from country to country. Technologies that are included in one smart grid concept are not necessarily included in another.

Motivation for smart grids Smart grids are generally expected to cope with the most pressing problems and challenges of many power systems more effectively and efficiently than conventional grid technologies. Smart grids primarily aim at delivering enhanced levels of reliability and security of supply, facilitating the balancing of electricity generation and consumption, increasing the utilization rate of power system components, and reducing investments in the conventional (primary) grid infrastructure. Smart grid technologies can be used, for example, to

- monitor and control electric power grids more effectively,

- facilitate the grid connection and operation of generators of all sizes and technologies,

- help to integrate electricity generated from intermittent RES,

- allow industrial, commercial, and residential consumers to play a part in optimizing the operation of the system by adjusting electricity consumption behavior according to supply, and

- provide consumers with greater information on their electricity consumption enabling electricity conservation [9].

The evolutionary character of smart grids Smart grids are not built from scratch. Rather, they evolve from conventional power grids which are upgraded with different kinds of innovative technologies and components. These technologies and components will be deployed at different periods in time depending on commercial attractiveness, compatibility with existing technologies, regulatory policies, and 


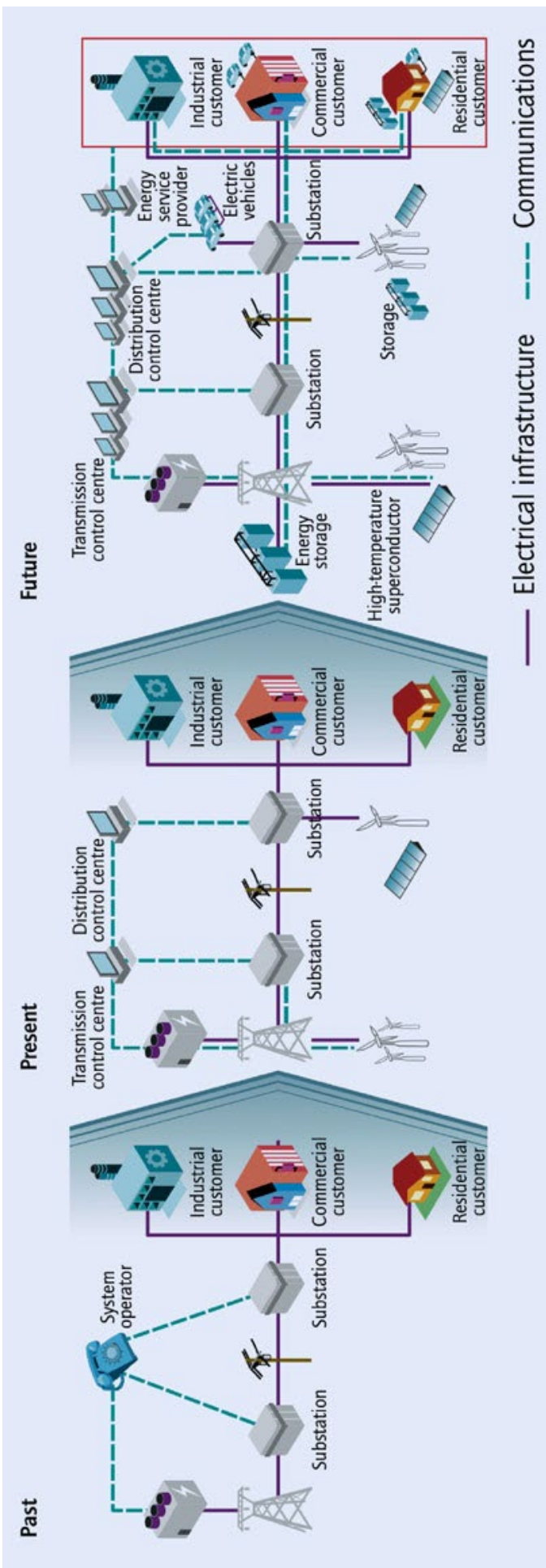

- Fig. 2.3 Development of smarter power systems (๑ OECD/ IEA [8]) investment frameworks. The evolutionary pathway of smart grid technologies is similar to that of other innovations: after major R\&D efforts, smart grid technologies are developed further in specific demonstration projects, tested in model cities or regions, and finally deployed on a larger scale.

Today's smart grid technology landscape is highly diverse with some technologies reaching already high levels of maturity and others still in a development process. Smart grid-related technologies with high levels of maturity are, for example, power plant communication and control modules, grid control systems, and advanced metering infrastructures (AMI). On the other hand, technologies such as wide area monitoring and control, distribution management, or electric vehicle charging infrastructure require more progress before they are mature enough for large-scale deployment [8].

Figure 2.3 visualizes a stylized evolutionary pathway of smart grids: in the past (left part of the illustration), electric power was mainly generated in thermal power plants. The status of high, medium, and low voltage grids was not remotely monitored. System operators were able to supervise substations at different voltage levels via rudimentary telecontrol or by means of manual patrol teams.

In the present (middle part of the illustration), large wind farms complement thermal power plants feeding in electricity at the high voltage (HV) level. The status of transmission grids and the associated substations is remotely monitored. The resulting status information is received in the transmission control center and can be used to monitor and control the grid. Medium voltage (MV) and low voltage (LV) grids, however, are not yet equipped with sophisticated monitoring technologies. The distribution control center only monitors the associated substations via telecontrol or by means of manual patrol teams. For the first time, small-sized wind farms and PV installations are being connected to distribution grids.

In the future (right part of the illustration), power grids at all voltage levels are expected to be equipped with sophisticated monitoring and control technologies. Status information, e.g. on electricity generation and consumption, will also be available for distribution grids. RES, energy storage installations, and electric vehicles will become an integral 
part of the future electric power system and will be able to exchange status information with the grid.

The role of governments in the smart grid development process Given the evolutionary character of smart grids and the low maturity levels of some smart grid technologies, both a systematic guidance and specific government support policies are essential to promote the development of smart grids. Exemplary government policies in this context are:

- Setting up a government long-term strategy for the development of the future electricity system to reduce investment risks for potential investors in $R \& D$ and deployment of smart grid technologies.

- Establishing network regulation for transmission and distribution grid operators which incentivizes them to invest in smart grid technologies.

- Promoting a non-discriminatory and technology-neutral management of and access to power system data to enable companies to develop innovative business models making use of this data.

- Partial government funding of $\mathrm{R} \& \mathrm{D}$ to increase the maturity level of smart grid technologies.

- Supporting smart grid-related standardization, defining technical guidelines and regulations to reduce the costs for deployment and integration of different smart grid components by ensuring interoperability.

- Promoting the exchange and collaboration between different government organizations, power sector companies, academia, associations, and other relevant actors to create a common understanding of smart grids.

The role of new market actors in the smart grid development process In Germany and many other countries, one important trend associated with the migration towards smart grids and the transition to an electricity system relying to an increasing extent on RES-E is a rise in the number of market actors in the electricity sector. New market actors (third parties or non-incumbents) can expand the horizontal market structure by entering into competition with established companies (incumbents) with regard to existing products or services (e.g. operators of renewable energy plants or new power retail companies). New market actors can also expand the vertical market structure by being pioneers offering products and/or services in new market sectors or niches (e.g. energy service companies or virtual power plant operators ${ }^{5}$ ) or in using existing knowledge and/or infrastructure from other sectors in an innovative way upgrading products and services in the electric power sector (e.g. ICT companies).

New market actors offer innovative products and services that were not supplied by established market actors before. In a smart grid context, nonincumbents create new business models and offer new products and services by making use of available power system information and infrastructure in an innovative way. To give some tangible examples for the power sector innovations that may be driven by third parties, - Sect. 4.4.2 highlights how nonincumbents in Germany create new business models in the smart grid development process. Note that the German evidence elaborated in $>$ Sect. 4.4.2 also demonstrates that new market actors might emerge due to government policies aimed explicitly at the promotion of competition.

In expanding the horizontal market structure, third parties contribute to an increased level of competition. Higher competition levels are usually considered to drive innovation, enable greater efficiency in the allocation of resources, increase cost efficiency of power sector enterprises with regard to their operations and investments, contribute to lower retail price levels, and stimulate innovation resulting in a higher variety of competitively priced products and services offered to the customer:

- With regard to the electric power sector, IEA analyzed the market liberalization process in several of its member countries and came to the conclusion that higher competition levels in the electric power sector contributed to a reduction of electricity prices for industrial consumers [10].

- With respect to the telecommunication sector, various empirical studies (including data from industrial and developing countries) found

5 Both new market actors are introduced in more detail in Sect. 4.4.2. 
that high competition levels significantly increased the overall sector performance and led to more landline and mobile telephone connections, lower tariffs, and more connection capacity [11], [12], [13]

- In the general economic literature, the relationship between competition and innovation has been examined in many theoretical and empirical studies. It is usually found that there is a kind of optimal market structure for R\&Dspending, innovation and diffusion. Neither very low nor very high competition levels are an innovation-friendly environment. A competitive market with a limited number of companies seems to promote innovation best [14].

Economic efficiency of smart grids The economic evaluation of smart grids is still ongoing. However, early evidence suggests that smart grids are an attractive solution compared to conventional grid expansion measures. A recent study summarizes the results of twelve smart grid cost-benefit analyses published between 2004 and 2012 in the United States, the UK, the Netherlands, Denmark, and the Czech Republic [15]. This overview shows that benefits of the investigated smart grid concepts outweigh costs in ten of twelve cases (with costs outweighing benefits in Denmark and the Czech Republic). Only four of these studies compared their results to costs and benefits of conventional grid expansion measures (increasing the grid capacity by traditional network expansion). These studies come to the conclusion that, from an economic point of view, investments in smart grid technologies are preferable to conventional expansion measures.

\section{Key findings}

- Governments strive to provide a reliable, affordable, and sustainable electricity supply for their economies. Yet, there are inherent conflicts between these three energy policy goals.

- Smart grids can be seen as an advanced way of operating grids supported by a broad set of new technologies in the areas of communication, metering, control, and automation. Smart grid-related operation concepts, technologies, and compo- nents can be used to upgrade the existing grid infrastructure and offer many new possibilities in grid management and control. Smart grids will be deployed at different periods in time depending on requirements of the particular power system, compatibility with existing technologies, regulatory policies, and investment frameworks.

- Recent evidence has shown that investments in smart grid technologies are economically preferable to conventional grid expansion measures. Moreover, smart grids represent a promising concept that could increase reliability and security of supply, facilitate the balancing of electricity generation and consumption, ease the grid integration of electricity generated from variable RES, and increase the utilization rate of power grid assets.

- Given the evolutionary character of smart grids and the still low maturity levels of some smart grid technologies, both systematic guidance and specific government support policies are essential to promote the development of smart grids.

- New market actors in the electric power sector are of crucial importance to promote innovation in the electric power sector and speed-up the development of smart grids.

\section{References}

1 R. Perman, Y. Ma, J. McGilvray and M. Common, Natural Resource and Environmental Economics, Harlow: Pearson Education Limited, 2003.

2 P. Krugman and R. Wells, Microeconomics, New York: Palgrave Macmillan, 2012.

3 S. Stoft, Power System Economics, Piscataway: The Institute of Electrical and Electronics Engineers, 2002.

4 S. C. Bhattacharyya, Energy Economics - Concepts, Issues, Markets and Governance, Heidelberg: Springer, 2011.

5 Bundesverband der Energie- und Wasserwirtschaft (BDEW), “Energie-Info Erneuerbare Energien und das EEG: Zahlen, Fakten, Grafiken (2013)," BDEW, Berlin, 2013.

6 C. Kost, J. N. Mayer, J. Thomsen, N. Hartmann, C. Senkpiel, S. Phillips, S. Nold, S. Lude and T. Schlegl, "Stromgestehungskosten Erneuerbare Energien," Fraunhofer-Institut für Solare Energiesysteme, Freiburg, 2013.

7 European Energy Exchange (EEX), "EEX Transparency in Energy Markets," EEX, November 2013. [Online]. Available: http://www.transparency.eex.com/de/. [Accessed May 15, 2014].

Open Access This chapter is distributed under the terms of the Creative Commons Attribution Noncommercial License, which permits any noncommercial use, distribution, and reproduction in any medium, provided the original author(s) and source are credited. 
8 International Energy Agency (IEA), "Technology Roadmap: Smart Grids," IEA, Paris, 2011.

9 International Electrotechnical Commission (IEC), "What is a Smart Grid?," IEC, November 2013. [Online]. Available: http://www.iec.ch/smartgrid/background/explained.htm. [Accessed November 15, 2013].

10 International Energy Agency (IEA), "Lessons from Liberalized Electricity Markets," IEA, Paris, 2005.

11 A. J. Ros, "Does Ownership or Competition Matter? The Effects of Telecommunications Reform on Network Expansion and Efficiency," Journal of Regulatory Economics, vol. 15, no. 1, pp. 65-92, 1999.

12 S. J. Wallsten, "An Econometric Analysis of Telecom Competition, Privatization, and Regulation in Africa and Latin America," Journal of Industrial Economics, vol. 49, no. 1, pp. 1-19, 2001.

13 C. Fink, M. Aaditya and R. Randeep, "An Assessment of Telecommunications Reform in Developing Countries," Information Economics \& Policy, vol. 15, no. 4, pp. 443-466, 2003.

14 P. Aghion, N. Bloom, R. Blundell, R. Griffith and P. Howitt, "Competition and Innovation: an Inverted-U Relationship," The Quarterly Journal of Economics, vol. 120, no. 2, pp. 701728, 2005.

15 C. Mahlstedt, "Bewertung international vorliegender Kosten-Nutzen-Analysen zur Errichtung eines intelligenten Stromnetzes (Smart Grid)," Carl von Ossietzky Universität Oldenburg, Oldenburg, 2013.

16 T. Luhmann and N. Vogel, "EPM-Referenzmodell - Grundlage für ein marktgerechtes Leistungsportfolio für die Energiewirtschaft," Unpublished Manuscript, Oldenburg, 2010.

17 E. Hirst and B. Kirby, "Electric Power Ancillary Services," Oak Ridge National Laboratory, Oak Ridge, 1996.

18 S. Dinda, "Environmental Kuznets Curve Hypothesis: A Survey," Ecological Economics, vol. 49, no. 4, pp. 431-455, 2004. 